\title{
Helmut Madjar, Ellen Mendelson: The practice of breast ultrasound. Techniques - findings - differential diagnosis, 2nd edition
}

\author{
Thieme, Stuttgart New York, 2008, ISBN: 978-3-13-124342-3
}

\author{
Maurizio Sacco $\cdot$ Luigi Mansi
}

Published online: 4 February 2009

(C) Springer-Verlag 2009

This book comes at an opportune time, when breast ultrasound examinations are increasing on a worldwide basis due to the availability of high-resolution systems. In recent years we have witnessed a revolution in imaging of the breast also determined by the introduction to the field of new techniques such as magnetic resonance imaging (MRI); but sonography still plays an important role in patient management and is also the method of choice for interventional procedures.

The publication of a comprehensive text written by two of the leaders in this field is therefore an important contribution, as it should fill an immediate need.

The experience of Dr H. Madjar and Dr E. Mendelson in continuing education has established their reputation as two of the leading authorities in breast sonography.

The book is structured to comply with the requirements of a three-tiered course of instruction in breast sonography, covering material at the basic, intermediate and advanced levels. The first level is based on the description of the basic principles, the examination technique, the BI-RADS system (Breast Imaging Reporting and Data System) and the sonographic anatomy of the breast and axilla. The intermediate course offers an overview of the features of the differential diagnosis of some benign and malignant findings. The advanced course describes the role of sonography in preoperative staging, in screening and in follow-up. Finally the book has a wealth of accessible information about interventional sonography, three-dimensional sonography, Doppler sonography and the use of contrast agents.

The format of the book is based on the progressive course levels of the guidelines of the German Society for Ultrasound in Medicine (DEGUM) and is in accordance with all international standards.

This second edition of the book has been revised to include North American practice patterns; therefore indications for breast sonography and the technical standards outlined in this text are in accord with those of the American College of Radiology (ACR).

Added to this edition is the presentation of the ACR's BI-RADS for sonography, one of three multimodality lexicons based on a feature analytical approach used in standardizing description, reporting and lesion assessment. The format is intended to make it easy for the novice to learn about breast sonography, but it is also designed to provide a quick and practical reference for the experienced sonologist. A particularly commendable aspect of the book is that it helps standardize the examination technique and the interpretation of findings.

This text is a timely addition to the literature and provides a reference that will be useful to any specialist who performs or is interested in starting to perform breast sonography.

\footnotetext{
M. Sacco $(\bowtie) \cdot$ L. Mansi

Naples, Italy

e-mail: ataualpamasa@libero.it

L. Mansi

e-mail: luigi.mansi@unina2.it
} 